\title{
Livin promotes the progression and metastasis of breast cancer through the regulation of epithelial-mesenchymal transition via the $\mathrm{p38} / \mathrm{GSK} 3 \beta$ pathway
}

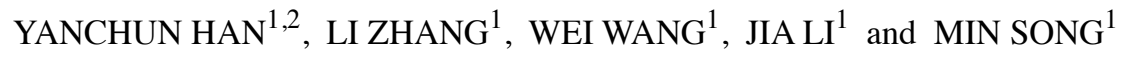 \\ ${ }^{1}$ Department of Pathology, The First Affiliated Hospital and College of Basic Medical Sciences, China Medical University, \\ Shenyang, Liaoning $110001 ;{ }^{2}$ Department of Pathology, Binzhou Medical University, Yantai, Shandong 264000, P.R. China
}

Received March 18, 2017; Accepted August 22, 2017

DOI: 10.3892/or.2017.6017

\begin{abstract}
Epithelial-mesenchymal transition (EMT) plays a pivotal role in the invasion and metastasis of breast cancer. Livin is a recently identified member of the inhibitors of the apoptosis protein family, which has been revealed to facilitate the progression of several types of cancer. However, the role of Livin in EMT and metastasis of breast cancer and its underlying mechanisms are not fully elucidated. In the present study, the levels of Livin mRNA and protein expression were found to be elevated in breast cancer tissues and cell lines. In addition, Livin expression was positively correlated with TNM stage and lymph node metastasis in total and triplenegative breast cancer (TNBC) cases. Livin overexpression enhanced the migratory and invasive abilities of the MCF-7 cells, accompanied by increases in vimentin, $\mathrm{N}$-cadherin, Snail, MMP-2 and MMP-7 and a decrease in E-cadherin. Conversely, the downregulation of Livin had the opposite effect in MDA-MB-231 cells. Furthermore, the upregulation of Livin expression markedly stimulated the activation of the $\mathrm{p} 38 / \mathrm{GSK} 3 \beta$ pathway, while the downregulation of Livin expression clearly suppressed the activation of the p38/GSK3 $\beta$ pathway. In conclusion, our results revealed that Livin induced EMT through the activation of the p38/GSK3 $\beta$ pathway, which in turn promoted the progression and metastasis of breast cancer, especially for TNBC.
\end{abstract}

\section{Introduction}

Breast cancer is the most prevalent female cancer worldwide, and most deaths from breast cancer are due to metastasis $(1,2)$. Triple-negative breast cancer (TNBC) which is negative for

Correspondence to: Professor Min Song, Department of Pathology, The First Affiliated Hospital and College of Basic Medical Sciences, China Medical University, Shenyang, Liaoning 110001, P.R. China E-mail: songmin6@sohu.com

Key words: Livin, epithelial-mesenchymal transition, p38, GSK3 $\beta$, breast carcinoma the estrogen receptor (ER), the progesterone receptor (PR) and the human epidermal growth factor receptor-2 (HER-2), presents the highest risk of recurrence and metastasis $(3,4)$.

Studies have revealed that epithelial-mesenchymal transition (EMT) is a critical step in tumor invasion and metastasis. During the process of EMT, cancer cells lose their epithelial phenotypes and gain mesenchymal characteristics (5-7). Breast cancer cells acquire increased migratory and invasive potential through EMT (8). Our understanding of the molecular mechanisms of this process may provide effective therapeutic strategies for reducing breast cancer metastasis.

Livin is the most recently identified member of the inhibitors of the apoptosis protein (IAP) family. Numerous evidence has demonstrated that Livin is associated with a high degree of malignancy and with poor prognosis in cancer patients (9-11). Livin inhibits cell apoptosis by binding to the regulators of apoptosis and promotes cell proliferation, migration and invasion (12). A recent study revealed that Livin was involved in the regulation of EMT in colorectal cancer cells (13). However, the role of Livin in EMT and metastasis of breast cancer and its relevant mechanisms remain unclear.

In the present study, we investigated the effect of Livin on the progression and metastasis of breast cancer. Our findings demonstrated that Livin promoted invasion and metastasis in breast cancer through the regulation of EMT by activating the p38/GSK3 $\beta$ pathway, especially in TNBC.

\section{Materials and methods}

Tissue samples. The paraffin-embedded specimens of 150 breast cancer tissues (33 tissues of TNBC cases and 117 of non-TNBC cases) and 30 paracancerous tissues were selected from the First Affiliated Hospital of China Medical University and the Affiliated Hospital of Binzhou Medical University. The 16 pairs of primary breast cancer and the corresponding adjacent non-tumor tissues were acquired from the First Affiliated Hospital of China Medical University. The collected fresh samples were immediately stored at $-80^{\circ} \mathrm{C}$ for protein and RNA extraction. None of the patients had undergone radiotherapy and chemotherapy prior to the sample collection. Informed consent was obtained prior to surgery, from all enrolled patients. The 
study was approved by the Medical Ethics Committee of China Medical University and Binzhou Medical University.

Cell culture. Human breast cancer cell lines MCF-7 and MDA-MB-231, and normal human breast epithelial cell line MCF-10A were obtained from the Cell Bank of the Chinese Academy of Sciences (Shanghai, China). MCF-7 and MCF-10A cells were cultured in Dulbecco's modified Eagle's medium (DMEM; Gibco, Grand Island, NY, USA) and MDA-MB-231 cells were grown in Leibovitz's L-15 medium (Gibco). Both media were supplemented with $10 \%$ fetal bovine serum (FBS; Biological Industries Israel Beit Haemek Ltd., Israel) and $1 \%$ Pen-Strep solution in a $5 \% \mathrm{CO}_{2}$ humidified incubator at $37^{\circ} \mathrm{C}$.

Quantitative real-time RT-PCR. Total RNA was extracted from the breast tissues and cells using RNAiso Plus (Takara, Dalian, China) and reverse-trancribed to synthesize cDNA using the PrimeScript TMRT reagent kit (Takara). The expression of Livin was determined with SYBR ${ }^{\circledR}$ Premix Ex Taq ${ }^{\mathrm{TM}}$ II (Takara) using the 7900HT Fast Real-Time PCR System (Applied Biosystems, Foster City, CA, USA). The quantification of Livin was normalized to GAPDH using the $\Delta \Delta \mathrm{Ct}$ method. The primers for Livin were 5'-GACAGAGGAGGA AGAGGAGGA-3'/5'-TCAGCGGCCAGTCATAGAAG-3' and for GAPDH were 5'-GCACCGTCAAGGCTGAGAAC3'\% 5'-TGGTGAAGACGCCAGTGGA-3'.

Western blot analysis. Total proteins from breast tissues and cells were extracted in RIPA buffer and quantified using the Bradford method. Lysates containing $60 \mu \mathrm{g}$ of total proteins were subjected to $10 \%$ SDS-PAGE and subsequently transferred onto polyvinylidene fluoride (PVDF) membranes. The membranes were blocked with $5 \%$ non-fat milk powder or $5 \%$ bovine serum albumin (BSA) for $2 \mathrm{~h}$ at room temperature. Subsequently, the blots were probed overnight at $4^{\circ} \mathrm{C}$ with indicated antibodies against Livin, Snail, Slug, MMP-2 and MMP-7 (all 1:500 diluted; Santa Cruz Biotechnology, Santa Cruz, CA, USA), E-cadherin (1:500 diluted; Wuhan Boster Biological Technology, Ltd., Wuhan, China), vimentin (1:500 diluted; Bioss, Beijing, China), N-cadherin (1:500 diluted; Bioss), p38, p-p38, GSK3 $\beta$, p-GSK3 $\beta$, p-ATF2 (all 1:1,000 diluted; Cell Signaling Technology, Beverly, MA, USA), GAPDH (1:2,000 diluted; ZSGB-Bio, Beijing, China) and incubated with appropriate secondary antibodies at room temperature for $2 \mathrm{~h}$. Immunolabeled proteins were detected with ECL (Thermo Fisher Scientific, Waltham, MA, USA). GAPDH was used as an internal control. To detect the expression of the relevant protein, the gray level of the indicated protein band was detected using ImageJ software (National Institutes of Health, Bethesda, MD, USA).

Immunohistochemistry. All specimens were made into paraffin sections with $4 \mu \mathrm{m}$ thickness. Immunohistochemistry staining was performed according to the Envision method (ZSGB-Bio, Beijing, China), following the manufacturer's protocol. The primary antibodies were rabbit polyclonal antibody against Livin (1:200), rabbit polyclonal antibody against E-cadherin, vimentin and $\mathrm{N}$-cadherin (1:300, respectively). For the negative controls, the primary antibodies were replaced by phosphate-buffered saline (PBS). Previously identified strongly staining breast tissue sections were used as positive controls. By multiplying the staining intensity and the percentage of positive cells, we evaluated the expression of Livin. Livin was mainly located in the cytoplasm. The intensity of staining was graded as 0-3 (0, none; 1 , weak; 2 , moderately strong; 3 , intense) and positive cell proportion was scored as $0-4$ (none, $0 ; 1-25 \%, 1 ; 26-50 \%, 2 ; 51-75 \%, 3 ; 76-100 \%, 4$ ). By multiplying these two factors, positive expression was indicated when the immunoreactive score was $\geq 2$. E-cadherin mainly localized in the cytomembrane and $\geq 50 \%$ cells with deep yellow or brown granules was scored as positive expression. $\mathrm{N}$-cadherin exhibited in the cytomembrane and (or) cytoplasm and $\geq 10 \%$ cells with deep yellow or brown granules was scored as positive expression. Vimentin mainly existing in the cytoplasm and $\geq 10 \%$ cells with deep yellow or brown granules was scored as positive expression $(14,15)$.

Plasmid construction and transfection. The pCMV6-mycLivin plasmid was purchased from Sino Biological Technology (Beijing, China), and the pCMV6-myc empty vector was purchased from Origene Technology (Rockville, MD, USA). Livin-siRNA and NC-siRNA were purchased from Santa Cruz Biotechnology. Transfection was carried out using the Lipofectamine 3000 reagent (Invitrogen, Carlsbad, CA, USA) according to the manufacturer's instructions.

Immunofluorescence staining. Cells were fixed with $4 \%$ paraformaldehyde and blocked with 5\% BSA. The primary antibodies against E-cadherin, vimentin and $\mathrm{N}$-cadherin (1:100, respectively) were incubated overnight at $4^{\circ} \mathrm{C}$. The following day, the cells were incubated with FITC-conjugated secondary antibodies in the dark at room temperature for $2 \mathrm{~h}$. The coverslips were incubated with DAPI for nuclear counterstaining. The results were observed using a fluorescence microscope.

Wound healing assay. When cell confluency reached $\sim 90 \%$ after transfection, wounds were created in the confluent cells using a $200-\mu 1$ pipette tip. The cells were rinsed with PBS to remove any free-floating cells and debris. Medium was subsequently added and culture plates were incubated at $37^{\circ} \mathrm{C}$. Wound healing within the scrape lines was observed at different time-points and representative scrape lines for each cell line were photographed.

Cell migration assay. Cells $\left(3 \times 10^{4}\right)$ were plated in the upper Transwell chamber (Corning, Lowell, MA, USA) in $100 \mu \mathrm{l}$ medium with $2 \%$ fetal bovine serum (FBS) after they were cultured to the exponential phase. The lower chamber was filled with $600 \mu \mathrm{l}$ medium containing $20 \%$ FBS as a chemoattractant. After a 24-h incubation, the migrated cells were fixed with cold methanol and stained with hematoxylin. The stained migrated cells were scored and photographed under microscopic observation.

Matrigel invasion assay. An invasion assay was performed using the Transwell chamber precoated with diluted Matrigel (BD Biosciences, San Jose, CA, USA). Cells $\left(1 \times 10^{5}\right)$ in $100 \mu \mathrm{l}$ medium containing $2 \%$ FBS were seeded into the upper 


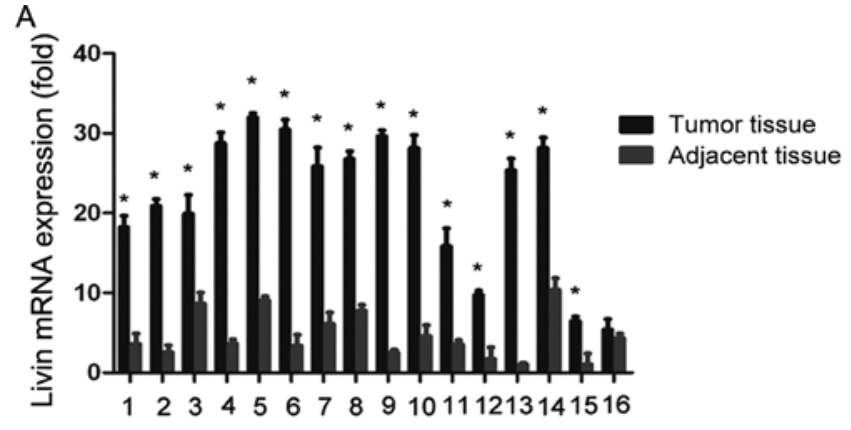

B

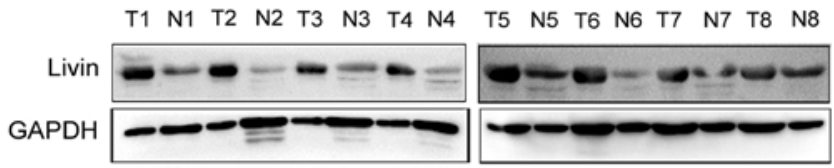

T9 N9 T10 N10T11N11 T12 N12 T13 N13T14N14T15 N15T16 N16
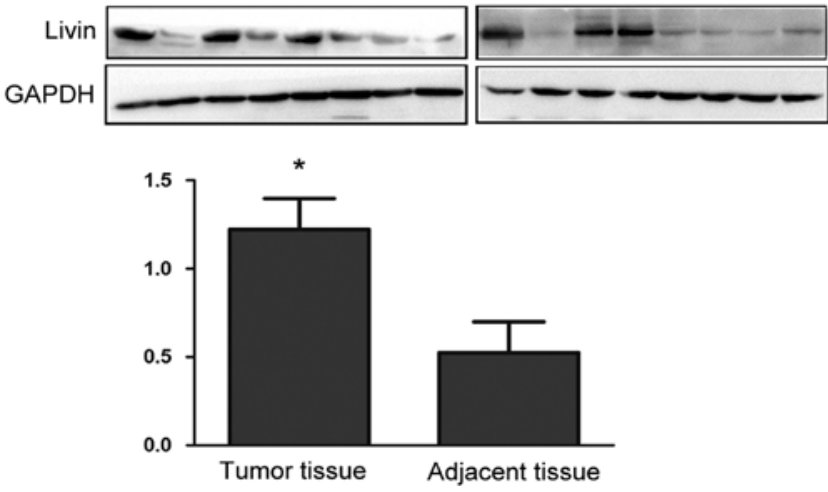

Figure 1. Livin is overexpressed in breast cancer tissues. The expression of Livin in breast cancer tissues and adjacent non-tumor tissues as determined by (A) qRT-PCR and (B) western blot analysis. Both the mRNA and the protein expression levels of Livin were markedly upregulated in breast cancer tissues compared with that in paired non-tumor tissues $\left({ }^{*} \mathrm{P}<0.05\right)$.

chamber, whereas the lower chamber was filled with $600 \mu \mathrm{l}$ medium containing 20\% FBS. The remaining experimental procedures were in accordance with the cell migration assay.

Statistical analysis. All statistical analyses were performed using the SPSS 16.0 statistical software (SPSS, Chicago, IL, USA). The immunohistochemistry results were analyzed using the Chi-square test and the Pearson's correlation test. Differences between groups were assessed by the Student's t-test. Data were processed using GraphPad Prism 5.0 software (GraphPad Software, Inc., La Jolla, CA, USA). P<0.05 was considered to indicate a statistically significant difference.

\section{Results}

Livin is overexpressed in breast cancer tissues. The expression of Livin at transcriptional and translational levels was assessed in fresh breast tissues by quantitative real-time RT-PCR (qRT-PCR) and western blot analysis. As shown in Fig. 1A and B, Livin mRNA and protein expression were markedly upregulated in breast cancer tissues compared with that in paired non-tumor tissues.

To ascertain this result, an immunohistochemistry assay was employed to detect the expression of Livin in paraffin-embedded specimens. The results revealed
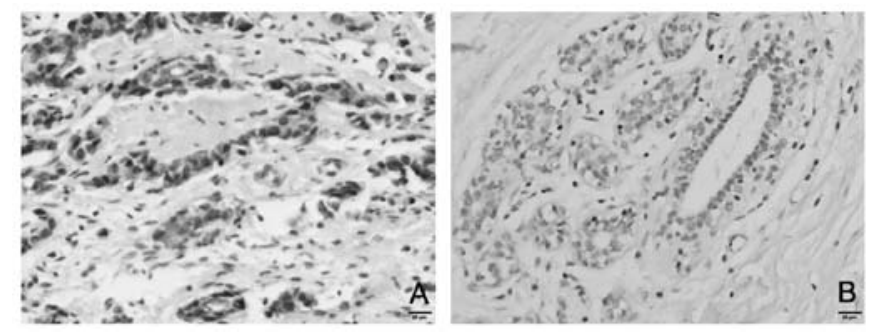

Figure 2. Expression of Livin in breast cancer and adjacent non-tumor tissues by immunohistochemistry. (A) Livin was strongly positive in breast cancer tissues (magnification, x400). (B) Livin was negatively or weakly positive in adjacent non-tumor breast tissues (magnification, $\mathrm{x} 400$ ).
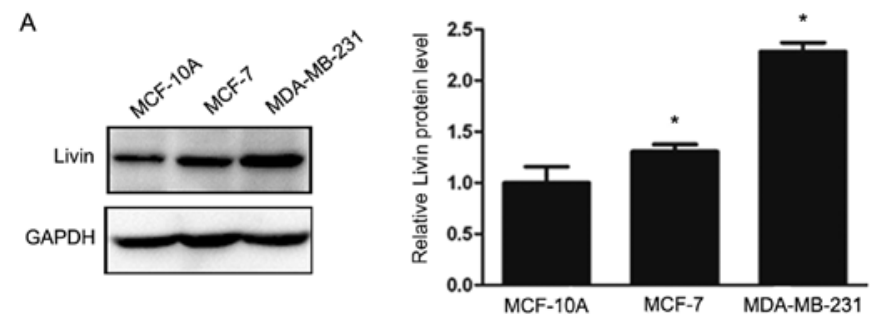

B

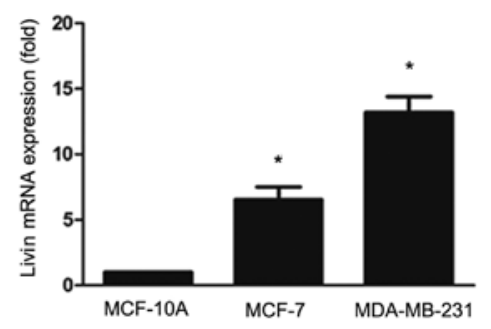

Figure 3. Livin is overexpressed in breast cancer cells. Livin expression at the protein and mRNA levels in breast cancer cell lines MCF-7 and MDA-MB-231 and normal breast epithelial cell line MCF-10A as determined by (A) western blot analysis and (B) qRT-PCR. Livin expression at the protein and mRNA levels was significantly elevated in MDA-MB-231 and MCF-7 cells compared with those in MCF-10A cells $\left({ }^{*} \mathrm{P}<0.05\right)$.

that Livin was mainly located in the cytoplasm of cancer cells in breast cancer tissues (Fig. 2). The rate of positive expression of Livin in breast cancer tissues (59.3\%) was significantly higher than that in adjacent non-tumor tissues $(23.3 \%, \mathrm{P}<0.001)$.

Livin is overexpressed in breast cancer cell lines. We detected the expression of Livin in the breast cancer cell lines MCF-7 and MDA-MB-231 and in the normal breast epithelial cell line MCF-10A using western blot analysis and qRT-PCR (Fig. 3). The levels of Livin expression were significantly elevated in the MDA-MB-231 and MCF-7 cells compared to those in the MCF-10A cells.

Livin expression is correlated with clinicopathological features of breast cancer. We analyzed the correlation between Livin expression and the clinicopathological features of the breast cancer patients (Table I). Livin expression was significantly positively associated with TNM stage and lymph node metastasis in the breast cancer cases, especially in TNBC $(\mathrm{P}<0.01)$. In contrast, there was no marked correlation between Livin expression and patient age, tumor size, or 
Table I. Association of Livin expression with clinicopathological factors in breast cancer.

\begin{tabular}{|c|c|c|c|c|c|c|c|c|c|}
\hline \multirow{2}{*}{$\begin{array}{l}\text { Clinicopathological } \\
\text { features }\end{array}$} & \multicolumn{3}{|c|}{ Livin (total) } & \multicolumn{3}{|c|}{ Livin (TNBC) } & \multicolumn{3}{|c|}{ Livin (non-TNBC) } \\
\hline & Negative & Positive & P-value & Negative & Positive & P-value & Negative & Positive & P-value \\
\hline \multicolumn{10}{|l|}{ Age (years) } \\
\hline$\leq 45$ & 34 & 42 & & 5 & 14 & & 29 & 28 & \\
\hline$>45$ & 27 & 47 & 0.304 & 5 & 9 & 0.561 & 22 & 38 & 0.121 \\
\hline \multicolumn{10}{|l|}{ Tumor size $(\mathrm{cm})$} \\
\hline$<2$ & 23 & 27 & & 3 & 6 & & 20 & 21 & \\
\hline $2-5$ & 30 & 42 & & 6 & 10 & & 24 & 32 & \\
\hline$>5$ & 8 & 20 & 0.314 & 1 & 7 & 0.442 & 7 & 13 & 0.588 \\
\hline \multicolumn{10}{|l|}{$\begin{array}{l}\text { Histopathological } \\
\text { grade }\end{array}$} \\
\hline I & 20 & 15 & & 4 & 2 & & 16 & 13 & \\
\hline II & 28 & 45 & & 4 & 14 & & 24 & 31 & \\
\hline III & 13 & 29 & 0.057 & 2 & 7 & 0.101 & 11 & 22 & 0.224 \\
\hline \multicolumn{10}{|l|}{ TNM stage } \\
\hline I & 26 & 16 & & 5 & 1 & & 21 & 15 & \\
\hline II & 26 & 49 & & 3 & 14 & & 23 & 35 & \\
\hline III & 9 & 24 & 0.003 & 2 & 8 & 0.008 & 7 & 16 & 0.076 \\
\hline \multicolumn{10}{|l|}{$\begin{array}{l}\text { Metastatic lymph } \\
\text { node }\end{array}$} \\
\hline Negative & 39 & 31 & & 8 & 6 & & 31 & 25 & \\
\hline Positive & 22 & 58 & 0.000 & 2 & 17 & 0.004 & 20 & 41 & 0.014 \\
\hline
\end{tabular}

TNBC, triple-negative breast cancer.

histological differentiation $(\mathrm{P}>0.05)$. Furthermore, the rate of Livin expression in TNBC tissues was slightly higher than that in non-TNBC tissues. However, this difference was not statistically significant. In addition, Livin expression was higher in TNBC MDA-MB-231 cells than that in non-TNBC MCF-7 cells. These results suggested that Livin expression is positively associated with the progression and metastasis of breast cancer and that Livin plays a more important role in TNBC.

Livin promotes migration and invasion in breast cancer cells. To explore whether Livin affects the migration and invasion of breast cancer cells, we upregulated Livin expression by transfection of Livin in the non-TNBC cell line MCF-7, which has low Livin expression, and knocked down Livin expression by siRNA treatment in the TNBC cell line MDA-MB-231, which exhibits high Livin expression. Transfection efficiencies were assessed by western blot analysis and qRT-PCR, respectively (Fig. 4).

Wound healing, cell migration and Matrigel invasion assays were used to investigate the effect of Livin on cell migration and invasion abilities. The upregulation of Livin led to a significant increase in the migration and invasion of the MCF-7 cells. Conversely, the migratory and invasive abilities of the MDA-MB-231 cells were suppressed by the Livin-knockdown (Fig. 5).

Livin regulates EMT in breast cancer cells. EMT is highly correlated with tumor invasion and metastasis $(7,8)$. We therefore observed the influence of Livin on EMT in breast cancer cells. We examined the levels of several EMT-related factors using western blot analysis, after altering the expression of Livin. Livin overexpression caused a decrease in the expression of the epithelial marker E-cadherin and increases in the mesenchymal markers vimentin and $\mathrm{N}$-cadherin, as well as the EMT transcription factor Snail and the metastasis-associated factors MMP-2 and MMP-7. Depletion of Livin resulted in an increase in E-cadherin and decreases in vimentin and $\mathrm{N}$-cadherin as well as Snail, MMP-2 and MMP-7 (Fig. 6A). We further detected the expression of the EMT marker proteins by immunofluorescence assay and the results were consistent with those of the western blot analysis (Fig. 6B).

In addition, to determine whether Livin is associated with the EMT markers, we further performed immunohistochemical analysis of the samples from 33 cases of TNBC and 117 cases of non-TNBC (Table II). Correlation analysis revealed that Livin expression was positively correlated with the expression of vimentin and $\mathrm{N}$-cadherin and negatively correlated with that of E-cadherin in TNBC. In non-TNBC, enhanced expression of Livin was significantly associated with enhanced expression of vimentin and reduced expression of E-cadherin, while Livin expression was not significantly associated with the expression of $\mathrm{N}$-cadherin. These findings suggested that Livin induced EMT to promote cell migration and invasion in breast cancer cells.

The p38/GSK3 $\beta$ pathway is involved in the effect of Livin on EMT in breast cancer cells. Recent studies have revealed that the p38 and GSK $3 \beta$ pathways regulate EMT to promote progression and metastasis in several types of cancer $(16,17)$, activating p38 
A

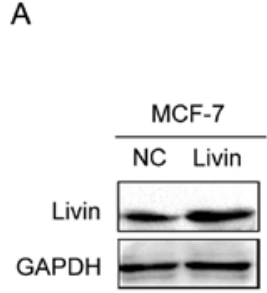

C

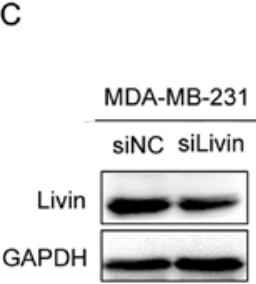

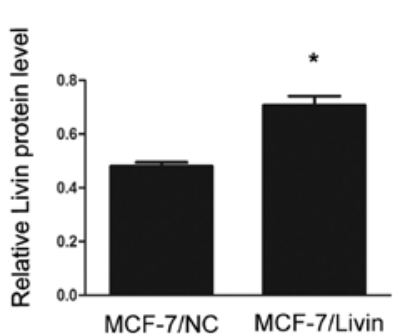

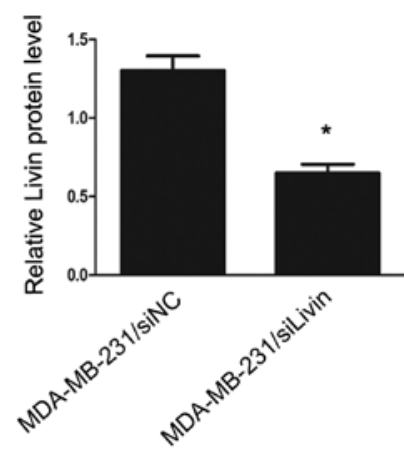

B

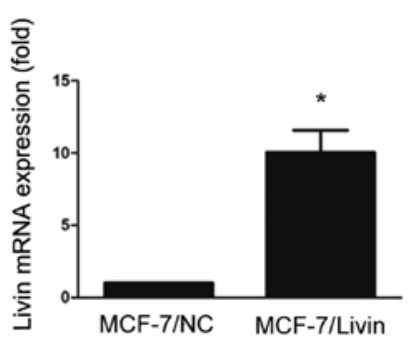

$\mathrm{D} \widehat{\mathrm{\theta}}$

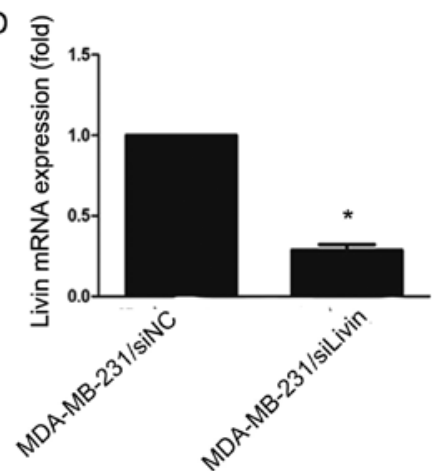

Figure 4. Transfection efficiency of Livin identified by western blot analysis and qRT-PCR. The expression of Livin protein and mRNA in MCF-7 cells transfected with Livin overexpression plasmids and control plasmids was detected by (A) western blot analysis and (B) qRT-PCR. The expression of Livin in MDA-MB-231 cells treated with siRNA against Livin and control siRNA was examined by (C) western blot analysis and (D) qRT-PCR.

A

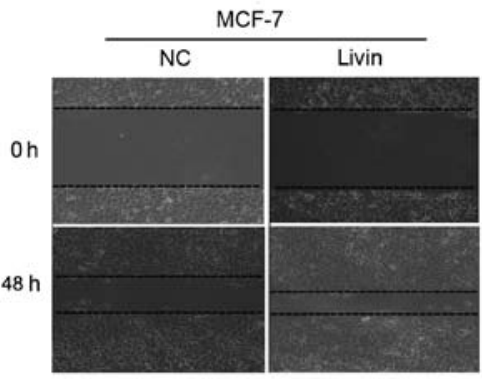

B
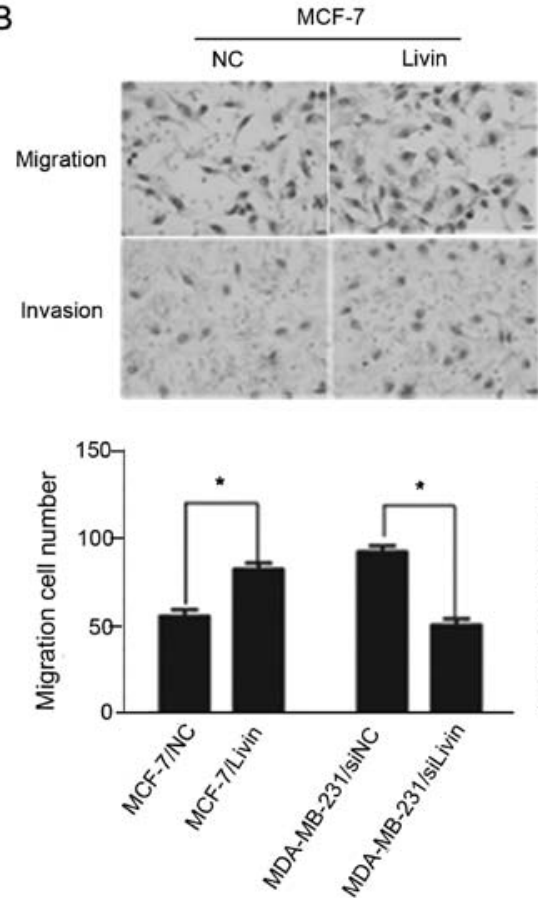
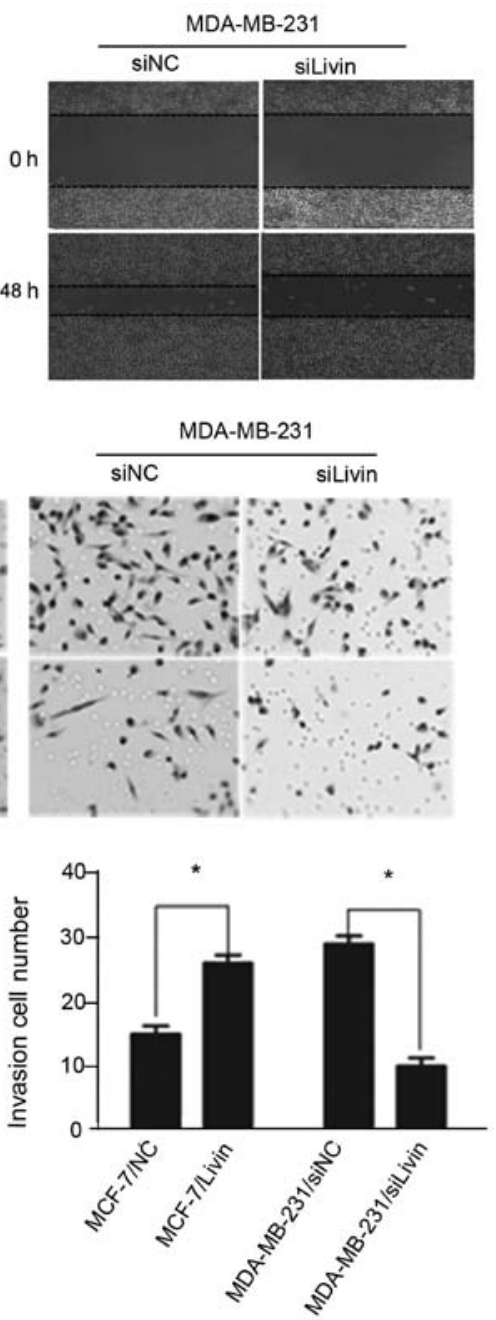

Figure 5. Change in Livin expression alters the migration and invasion of breast cancer cells. (A) Wound healing assay of cell migration. Scrape lines of each cell line of altered Livin expressions were photographed. (B) Migratory and invasive properties of cells as analyzed by cell migration and Matrigel invasion assay. " $\mathrm{P}<0.05$, compared with control groups. 
A

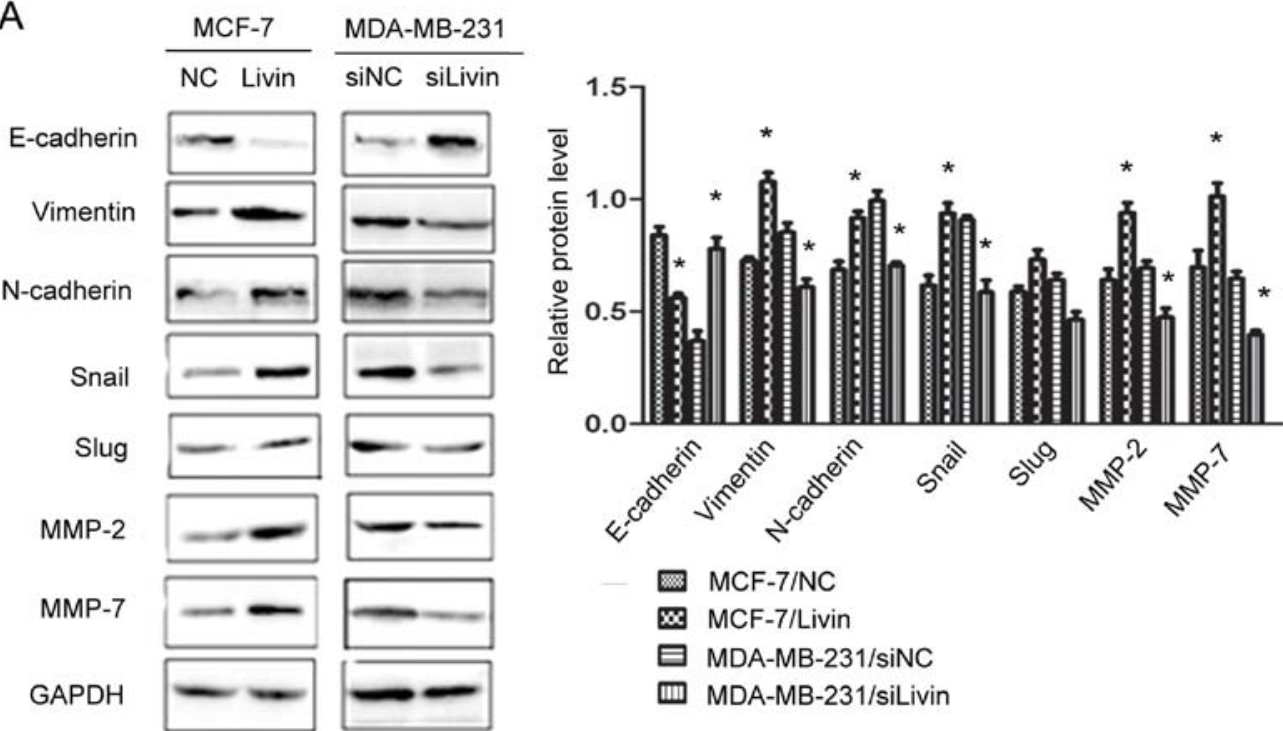

B

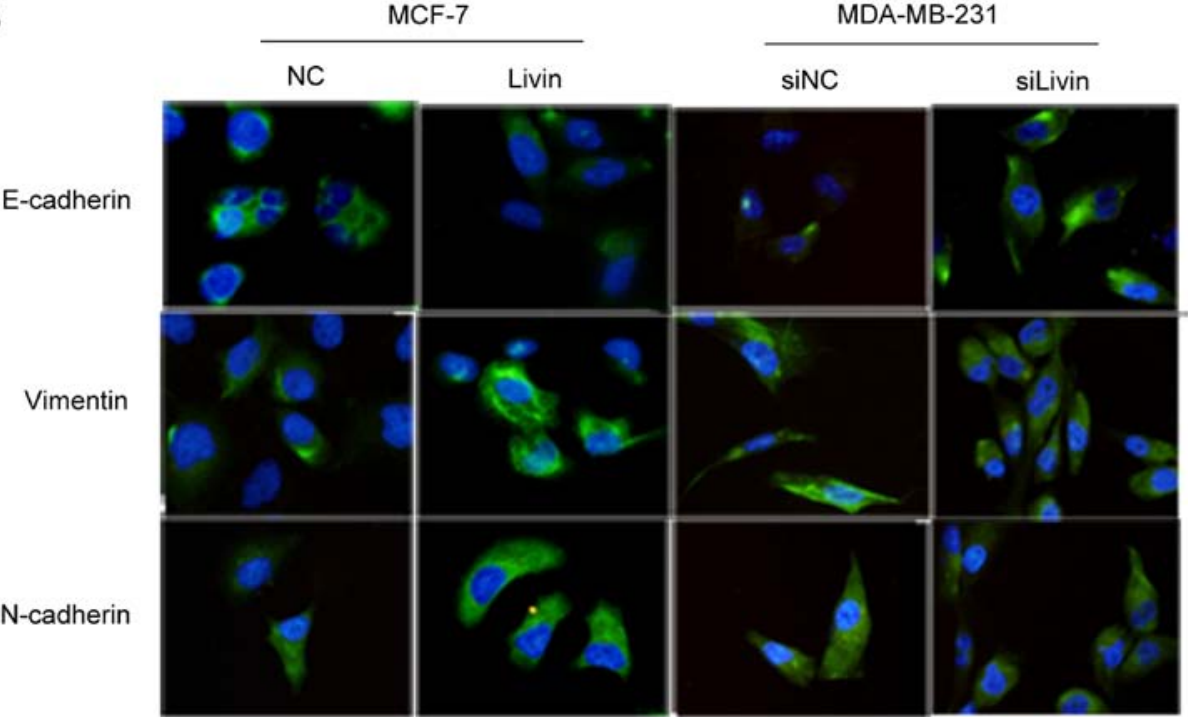

Figure 6. Livin regulates EMT in breast cancer cells. (A) Western blot analysis of EMT-related factors in MCF-7/NC, MCF-7/Livin, MDA-MB-231/siNC, MDA-MB-231/siLivin cells. (B) Immunofluorescence staining for E-cadherin, vimentin and N-cadherin in MCF-7/NC, MCF-7/Livin, MDA-MB-231/siNC, MDA-MB-231/siLivin cells.

Table II. Correlation between Livin and EMT marker proteins in breast cancer.

\begin{tabular}{|c|c|c|c|c|c|c|}
\hline \multirow{2}{*}{$\begin{array}{l}\text { EMT } \\
\text { markers }\end{array}$} & \multicolumn{3}{|c|}{ Livin (TNBC) } & \multicolumn{3}{|c|}{ Livin (non-TNBC) } \\
\hline & Negative & Positive & P-value & Negative & Positive & P-value \\
\hline \multicolumn{7}{|l|}{ E-cadherin } \\
\hline Negative & 1 & 13 & & 9 & 11 & \\
\hline Positive & 9 & 10 & 0.013 & 42 & 45 & 0.04 \\
\hline \multicolumn{7}{|l|}{ Vimentin } \\
\hline Negative & 10 & 13 & & 48 & 53 & \\
\hline Positive & 0 & 10 & 0.012 & 3 & 13 & 0.03 \\
\hline \multicolumn{7}{|l|}{$\mathrm{N}$-cadherin } \\
\hline Negative & 9 & 11 & & 43 & 46 & \\
\hline Positive & 1 & 12 & 0.023 & 8 & 20 & 0.066 \\
\hline
\end{tabular}

TNBC, triple-negative breast cancer. and inhibiting GSK $3 \beta$ to promote EMT. To explore the possible mechanism of Livin-induced EMT in breast cancer cells, we examined the expression of $\mathrm{p} 38 / \mathrm{GSK} 3 \beta$-associated factors. The overexpression of Livin in MCF-7 cells markedly enhanced the phosphorylation of $\mathrm{p} 38, \mathrm{ATF} 2$ and GSK3 $\beta$. In contrast, the knockdown of Livin in MDA-MB-231 cells clearly inhibited the phosphorylation of p38, ATF2 and GSK3 $\beta$ (Fig. 7A).

Moreover, we ascertained the above results using a specific inhibitor of p38, SB203580 (Cell Signaling Technology) and an effective inhibitor of GSK3 $\beta$, SB216763 (Cell Signaling Technology). SB203580 is a specific inhibitor of p38 that inhibits p38 catalytic activity by binding to the ATP binding pocket, but it does not inhibit phosphorylation of p38. SB216763 is an effective inhibitor of the GSK3 $\beta$ activity. Inactivation of GSK $3 \beta$ results in an increase in phosphorylated GSK $3 \beta$. GSK $3 \beta$ is a downstream target of p38 and inhibiting p38 downregulates phosphorylated GSK3 $\beta$ expression and enhances GSK3 $\beta$ activity. The increased 
A

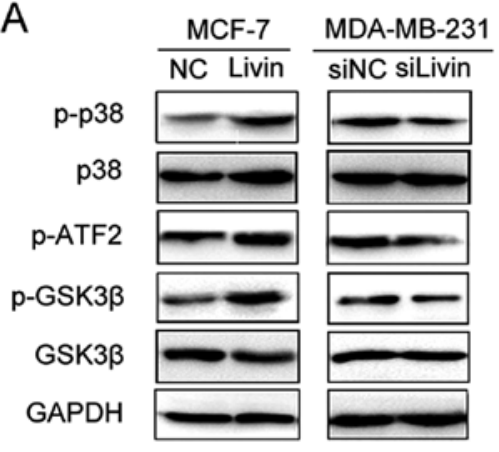

B

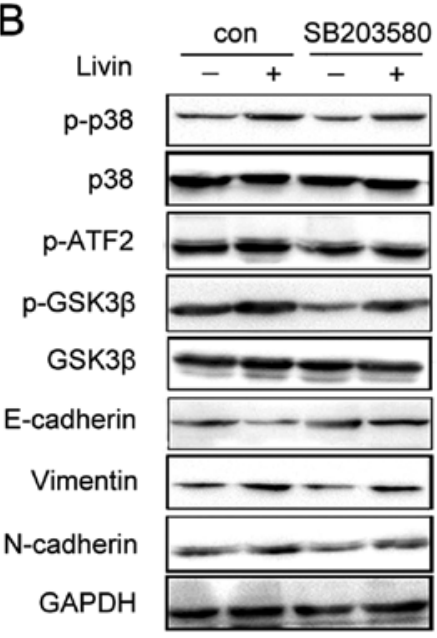

C

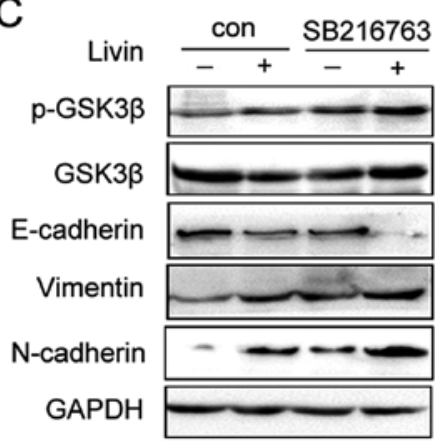

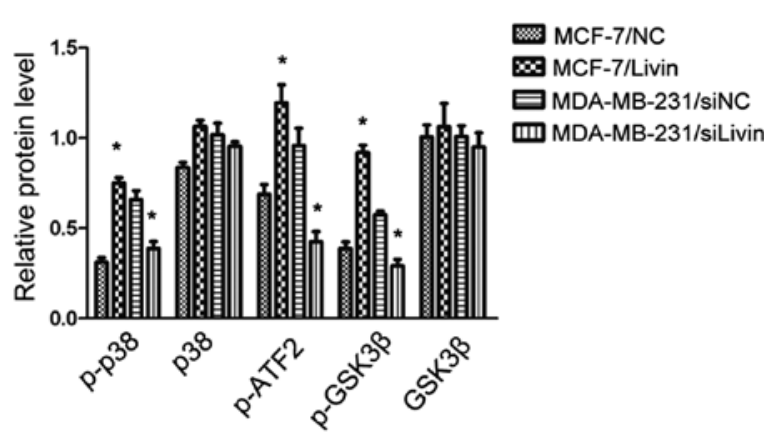
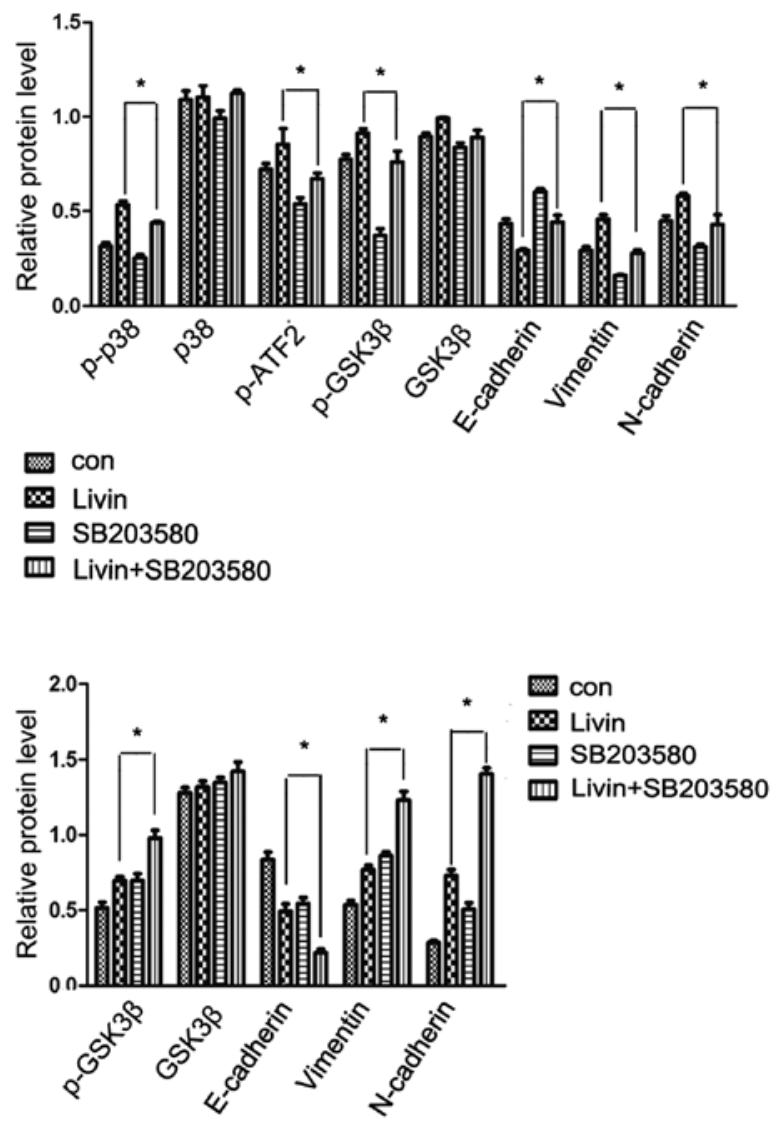

Figure 7. The p38/GSK3 $\beta$ pathway is involved in the effect of Livin on EMT in breast cancer cells. (A) The expression of p38/GSK3 $\beta$ pathway-related proteins and EMT marker proteins as detected by western blot analysis in MCF-7/NC, MCF-7/Livin, MDA-MB-231/siNC and MDA-MB-231/siLivin cells. (B) The expression of p38/GSK3 $\beta$ pathway-related proteins and EMT marker proteins as detected by western blot analysis in MCF-7 cells after pretreatment with the inhibitor of p38, SB203580. (C) The expression of GSK3 $\beta$ pathway-related proteins and EMT marker proteins as detected by western blot analysis in MCF-7 cells after pretreatment with the inhibitor of GSK3 $\beta$, SB216763.

expression of p-ATF2, p-GSK3 $\beta$, vimentin and N-cadherin was eliminated and the expression of E-cadherin was partially restored by SB203580 (Fig. 7B). When SB216763 was added to the medium after Livin was upregulated, the expression of p-GSK3 $\beta$, vimentin and $\mathrm{N}$-cadherin was further increased and E-cadherin expression was markedly reduced (Fig. 7C). These results indicated that Livin may activate the p38/GSK3 $\beta$ pathway to promote EMT in breast cancer cells.

\section{Discussion}

Livin has been recently recognized as a vital molecule that participates in the development and progression of malignant tumors, such as gastric (18), colorectal (19), prostate (20) and lung cancer (21). In the present study, our results revealed that Livin expression was increased in breast cancer tissues and cells. The expression of Livin was positively correlated with the TNM stage and lymph node metastasis in breast cancer, particularly in TNBC. Moreover, the overexpression of Livin enhanced the migratory and invasive abilities of the nonTNBC cell line MCF-7 and the knockdown of Livin had the opposite effect in the TNBC cell line MDA-MB-231. These results revealed that Livin has the potential to facilitate the progression and metastasis of breast cancer, especially in TNBC, indicating it may be a therapeutic target for breast cancer treatment. 
EMT is highly correlated with tumor development and progression. Through EMT, cancer cells break down the basement membrane (BM) and extracellular matrix (ECM), invading the blood or lymph vessels and spreading to other tissues and organs $(22,23)$. During the process of EMT, the expression of markers of the epithelial phenotype, such as E-cadherin, decreases, while the expression of markers of the mesenchymal phenotype, such as vimentin and $\mathrm{N}$-cadherin, increases (24-26). Several transcription factors (such as Snail and Slug) bind to the promoter regions of genes related to cell-cell adhesion and inhibit their transcription, which is the critical step in EMT (27-29). Additionally, EMT also leads to the reorganization of the ECM and EMT-inducing factors increase the expression of ECM proteins and proteases (such as MMPs) $(30,31)$. Therefore, although the potential mechanisms involved in EMT in breast cancer are not entirely clear, we can assess EMT initiation through the detection of these factors.

According to a recent study by Ge et al (13), Livin potentiated the migration and invasion of colorectal cancer cells by regulating EMT. Our study revealed that Livin overexpression upregulated Snail, vimentin, N-cadherin, MMP-2 and MMP-7 and downregulated E-cadherin. In contrast, Livin knockdown had the opposite effect. Further immunohistochemistry results also established that Livin expression was positively associated with EMT in breast cancer. These results demonstrated that the influence of Livin on breast cancer aggressiveness was correlated with the induction of EMT.

A wide variety of signaling pathways is implicated in the EMT process. The p38 pathway has been found to play an active role in the regulation of EMT $(16,32)$. Recently, Ou et al (33) revealed that the knockdown of Livin suppressed the invasion of gastric cancer cells by inhibiting the phosphorylation of p38. GSK3 $\beta$ has been reported as a downstream target of p38 (34) and also as a regulator of the EMT process $(17,35)$. Our results demonstrated that Livin expression markedly increased the phosphorylation of the $\mathrm{p} 38$ and GSK $3 \beta$ signaling proteins, revealing the activation of the $\mathrm{p} 38 / \mathrm{GSK} 3 \beta$ pathway in Livin-overexpressing breast cancer cells. In addition, the upregulation of vimentin and $\mathrm{N}$-cadherin expression was eliminated and E-cadherin expression was restored after the treatment of Livin-transfected cells with the inhibitor of p38. Similarly, vimentin and $\mathrm{N}$-cadherin were further elevated and E-cadherin expression was markedly decreased by the inhibitor of GSK $3 \beta$. Our findings revealed that Livin overexpression resulted in the activation of $\mathrm{p} 38$, which induced the phosphorylation of GSK3 $\beta$ and inhibited the GSK $3 \beta$ activity, ultimately contributing to the initiation of EMT. This observation revealed that Livin promoted EMT in breast cancer cells, at least partially, through the activation of the $\mathrm{p} 38 / \mathrm{GSK} 3 \beta$ pathway. However, the specific mechanism through which Livin affects this pathway remains unknown and requires further investigation. The present study is the first to demonstrate that Livin-induced EMT is, at least partially, regulated by the p38/GSK3 $\beta$ signaling pathway in breast cancer. Yet, it is also noteworthy that Livin regulates EMT in breast cancer through the activation of AKT signaling (36). Whether the AKT and p38/GSK3 $\beta$ signaling pathways involve crosstalk or whether they are independent of each other in Livin-induced EMT of breast cancer requires further investigation. In addition, other Livin-mediated pathways should be investigated to determine whether there are other links between Livin and EMT in breast cancer.

Collectively, our results indicated that Livin promoted the progression and metastasis of breast cancer through the regulation of EMT by activating the p38/GSK $3 \beta$ pathway. A deeper understanding of the role of Livin-induced EMT in breast cancer may provide effective targets for breast cancer therapy, especially in TNBC.

\section{References}

1. Stebbing $\mathbf{J}$ and Ellis P: An overview of drug development for metastatic breast cancer. Br J Nurs 21 (Sup4): S18-S22, 2012.

2. Jia LY, Shanmugam MK, Sethi G and Bishayee A: Potential role of targeted therapies in the treatment of triple-negative breast cancer. Anticancer Drugs 27: 147-155, 2016.

3. Saha P and Nanda R: Concepts and targets in triple-negative breast cancer: Recent results and clinical implications. Ther Adv Med Oncol 8: 351-359, 2016.

4. Tseng LM, Hsu NC, Chen SC, Lu YS, Lin CH, Chang DY, Li H, Lin YC, Chang HK, Chao TC, et al: Distant metastasis in triplenegative breast cancer. Neoplasma 60: 290-294, 2013.

5. Micalizzi DS, Farabaugh SM and Ford HL: Epithelial-mesenchymal transition in cancer: Parallels between normal development and tumor progression. J Mammary Gland Biol Neoplasia 15: 117-134, 2010.

6. Creighton CJ, Gibbons DL and Kurie JM: The role of epithelialmesenchymal transition programming in invasion and metastasis: A clinical perspective. Cancer Manag Res 5: 187-195, 2013.

7. Kotiyal S and Bhattacharya S: Epithelial mesenchymal transition and vascular mimicry in breast cancer stem cells. Crit Rev Eukaryot Gene Expr 25: 269-280, 2015.

8. Huang J, Li H and Ren G: Epithelial-mesenchymal transition and drug resistance in breast cancer (Review). Int J Oncol 47: 840-848, 2015.

9. Kenneth NS and Duckett CS: IAP proteins: Regulators of cell migration and development. Curr Opin Cell Biol 24: 871-875, 2012.

10. Argon A, Nart D, Oruç N, Coker A and Ozütemiz O: The prognostic significance of clinicopathological features and apoptosis inhibitor proteins in pancreas ductal adenocarcinoma. Acta Gastroenterol Belg 77: 229-234, 2014.

11. Jayakumar J and Anishetty S: Molecular dynamics simulations of inhibitor of apoptosis proteins and identification of potential small molecule inhibitors. Bioorg Med Chem Lett 24: 2098-2104, 2014.

12. Li CJ, Cong Y, Liu XZ, Zhou X, Shi X, Wu SJ, Zhou GX and $\mathrm{Lu}$ M: Research progress on the livin gene and osteosarcomas. Asian Pac J Cancer Prev 15: 8577-8579, 2014.

13. Ge Y, Cao X, Wang D, Sun W, Sun H, Han B, Cui J and Liu B: Overexpression of Livin promotes migration and invasion of colorectal cancer cells by induction of epithelial-mesenchymal transition via $N F-\kappa B$ activation. Onco Targets Ther 9: 1011-1021, 2016.

14. Ryu HS, Chung JH, Lee K, Shin E, Jing J, Choe G, Kim H, $\mathrm{Xu}$ X, Lee HE, Kim DG, et al: Overexpression of epithelialmesenchymal transition-related markers according to cell dedifferentiation: Clinical implications as an independent predictor of poor prognosis in cholangiocarcinoma. Hum Pathol 43: 2360-2370, 2012.

15. Ryu HS, Park DJ, Kim HH, Kim WH and Lee HS: Combination of epithelial-mesenchymal transition and cancer stem cell-like phenotypes has independent prognostic value in gastric cancer. Hum Pathol 43: 520-528, 2012.

16. Chen HH, Zhou XL, Shi YL and Yang J: Roles of p38 MAPK and JNK in TGF- $\beta 1$-induced human alveolar epithelial to mesenchymal transition. Arch Med Res 44: 93-98, 2013.

17. Zhang B, Yang Y, Shi X, Liao W, Chen M, Cheng AS, Yan H, Fang C, Zhang S, Xu G, et al: Proton pump inhibitor pantoprazole abrogates adriamycin-resistant gastric cancer cell invasiveness via suppression of Akt/GSK- $\beta / \beta$-catenin signaling and epithelial-mesenchymal transition. Cancer Lett 356: 704-712, 2015

18. Chung CY, Park YL, Kim N, Park HC, Park HB, Myung DS, Kim JS, Cho SB, Lee WS and Joo YE: Expression and prognostic significance of Livin in gastric cancer. Oncol Rep 30: 2520-2528, 2013. 
19. Wang Y, Li Y, Zhou B, Zhang WY, Guan JT, Wang R, Yang L, Xia QJ, Zhou ZG and Sun XF: Expression of the apoptosis inhibitor livin in colorectal adenoma-carcinoma sequence: Correlations with pathology and outcome. Tumour Biol 35: $11791-11798,2014$

20. Gu J, Ren L, Wang X, Qu C and Zhang Y: Expression of livin, survivin and caspase-3 in prostatic cancer and their clinical significance. Int J Clin Exp Pathol 8: 14034-14039, 2015.

21. Li J, Chen P, Li XQ, Bao QL, Dai CH and Ge LP: Elevated levels of survivin and livin mRNA in bronchial aspirates as markers to support the diagnosis of lung cancer. Int $\mathbf{J}$ Cancer 132: 1098-1104, 2013.

22. Campbell K and Casanova J: A common framework for EMT and collective cell migration. Development 143: 4291-4300, 2016.

23. Liu X and Fan D: The epithelial-mesenchymal transition and cancer stem cells: Functional and mechanistic links. Curr Pharm Des 21: 1279-1291, 2015

24. Lee JY and Kong G: Roles and epigenetic regulation of epithelialmesenchymal transition and its transcription factors in cancer initiation and progression. Cell Mol Life Sci 73: 4643-4660, 2016

25. Kawata H, Kamiakito T, Omoto Y, Miyazaki C, Hozumi Y and Tanaka A: RhoC upregulation is correlated with reduced E-cadherin in human breast cancer specimens after chemotherapy and in human breast cancer MCF-7 cells. Horm Cancer 5 : 414-423, 2014

26. Bastos LG, de Marcondes PG, de-Freitas-Junior JC, Leve F, Mencalha AL, de Souza WF, de Araujo WM, Tanaka MN Abdelhay ES and Morgado-Díaz JA: Progeny from irradiated colorectal cancer cells acquire an EMT-like phenotype and activate Wnt/ $\beta$-catenin pathway. J Cell Biochem 115: 2175-2187, 2014.

27. Muqbil I, Wu J, Aboukameel A, Mohammad RM and Azmi AS: Snail nuclear transport: The gateways regulating epithelial-to-mesenchymal transition? Semin Cancer Biol 27: 39-45, 2014.

28. Wang Y, Shi J, Chai K, Ying X and Zhou BP: The role of Snail in EMT and tumorigenesis. Curr Cancer Drug Targets 13: 963-972, 2013.
29. Guo Q, Ning F, Fang R, Wang HS, Zhang G, Quan MY, Cai SH and Du J: Endogenous Nodal promotes melanoma undergoing epithelial-mesenchymal transition via Snail and Slug in vitro and in vivo. Am J Cancer Res 5: 2098-2112, 2015.

30. Bouris P, Skandalis SS, Piperigkou Z, Afratis N, Karamanou K, Aletras AJ, Moustakas A, Theocharis AD and Karamanos NK: Estrogen receptor alpha mediates epithelial to mesenchymal transition, expression of specific matrix effectors and functional properties of breast cancer cells. Matrix Biol 43: 42-60, 2015.

31. Tao T, Shi Y, Han D, Luan W, Qian J, Zhang J, Wang Y and You Y; Chinese Glioma Cooperative Group (CGCG): TPM3, a strong prognosis predictor, is involved in malignant progression through MMP family members and EMT-like activators in gliomas. Tumour Biol 35: 9053-9059, 2014.

32. Liang Z, Wu R, Xie W, Geng H, Zhao L, Xie C, Wu J, Geng S, Li X, Zhu M, et al: Curcumin suppresses MAPK pathways to reverse tobacco smoke-induced gastric epithelial-mesenchymal transition in mice. Phytother Res 29: 1665-1671, 2015.

33. Ou JM, Ye B, Qiu MK, Dai YX, Dong Q, Shen J, Dong P, Wang XF, Liu YB, Quan ZW, et al: Knockdown of Livin inhibits growth and invasion of gastric cancer cells through blockade of the MAPK pathway in vitro and in vivo. Int J Oncol 44: 276-284, 2014.

34. Bikkavilli RK, Feigin ME and Malbon CC: p38 mitogen-activated protein kinase regulates canonical Wnt-beta-catenin signaling by inactivation of GSK3beta. J Cell Sci 121: 3598-3607, 2008.

35. Liang Y, Jing Z, Deng H, Li Z, Zhuang Z, Wang S and Wang Y: Soluble epoxide hydrolase inhibition ameliorates proteinuriainduced epithelial-mesenchymal transition by regulating the PI3K-Akt-GSK-3 $\beta$ signaling pathway. Biochem Biophys Res Commun 463: 70-75, 2015.

36. Li F, Yin X, Luo X, Li HY, Su X, Wang XY, Chen L, Zheng K and Ren GS: Livin promotes progression of breast cancer through induction of epithelial-mesenchymal transition and activation of AKT signaling. Cell Signal 25: 1413-1422, 2013. 